\title{
Surveying the Relationship between Personality Traits and Self-Esteem with Marital Satisfaction in Married Students of Islamic Azad University Students, City of Rasht, Guilan Province, Iran
}

\author{
Abbas Sadeghi' ${ }^{1}$ Fatemeh Kazem Zadeh Mozhdehi ${ }^{2}$ \\ ${ }^{1}$ Department of Educational Sciences, University of Guilan, Rasht, Iran \\ ${ }^{2}$ Islamic Azad University, Rasht Branch, Rasht, Iran \\ Email: asadeghi1394@gmail.com,fkazemzade.mozhdehi@gmail.com
}

Received 2 March 2016; accepted 9 May 2016; published 12 May 2016

Copyright (C) 2016 by authors and Scientific Research Publishing Inc.

This work is licensed under the Creative Commons Attribution International License (CC BY).

http://creativecommons.org/licenses/by/4.0/

(c) (i) Open Access

\begin{abstract}
This research was conducted with the purpose of surveying the relationship between personality traits and self-esteem with marital Satisfaction. In this research statistic population includes all married of Islamic Azad University students of City of Rasht and research sciences in 2013-2014 academic semester that 10,485 students are educating in free university and research science. Morgan table was used for assigning the sample size. With regard to this table, sample size 714 persons were selected. Simple random method has been used for assigning testers. Questionnaires of five factor personality questionnaire (short from), cooper smith self-esteem questionnaire and Enrich marital satisfaction questionnaire were used for gathering information. Research findings were analyzed by person correlation coefficient, linear Regression. Results show that there was no meaningful relationship between neuroticism, extroversion, cheerfulness, and conscientious with marital satisfaction $(P>\mathbf{0 . 0 1})$. Also there was no meaningful relationship between factors of family, public, social and job self-esteem with marital satisfaction $(P>0.01)$.
\end{abstract}

\section{Keywords}

Personality Traits, Marital Satisfaction, Self-Esteem 


\section{Introduction}

Many years it has been pointed to this fact that, marriages are perfect which both parties almost have different aspects in common such as habits, attitudes, preferences, social and economy occasion and personality traits and in the other words they are in the same level. Regarding to the issues that couples are faced in life today and increasing divorce statistics, nonconformity of personality traits and mis-understating between couples and their dissatisfaction from their life are very important, so in this research we want to know that is there a relationship between personality traits and self-esteem with marital satisfaction?

Cooper (1967) concluded in his researches that high self-esteem makes the person strength in coping with different kinds of problem and life issues and mental pressures. Self-esteem is a factor that can impact of persons understanding, demonstrating and emotional actions and also can be determiner factor in amount of making stress and events; self-esteem is a series of feedbacks and beliefs that person expresses in his relationship with outside world. That is expressing disapprove of person toward expecting success and accepting and reacting to personal determiners.

Researches have neglected the intrapersonal factors that are personality traits and features that influence on couples' satisfaction from marriage. One of the most important and influential model in surveying the personality traits in recent decades has been five factors model that has specified the research aspect in personality more than others (Parvin \& John, 2002).

Research in marriage has been started with focus on couple personality traits. Many researches have been conducted about this issue on different samples in all over the world; for example Solomon et al. (2014) research results showed that personality traits can predict separation in a relationship.

The general quality of a person relationship can be formed by help of these features that will influence on probability of separation in relationship. Tackett et al. (2013) showed that higher levels of shyness have high correlation with less self-esteem and less satisfaction. This difference between results can be indicative of change in lifelong, extent of neuroticism influence on divorce, or overconfidence in previous study, and or mixture of three cases. Specht et al. (2014) recognized the marital satisfaction as an important variable for explaining mechanism and interpersonal differences in mature personality. The results showed that people with more satisfaction have experienced more positive changes in their emotional stability, agreement and conscientious and these positive changes in life satisfaction had relation with positive personality changes. Moreover, mature processes have been considered for people who have confronted the transmission of social role such as marriage, child birth, or entrance to job market once more, differential effects on importance of life satisfaction emphasized on personality.

Bloch et al. (2014) research results indicted the benefits of adjusting negative emotions during challenge for increasing life satisfaction and the role of woman was regarded as the mediation. South et al. (2014) found that symbols PD create considerable prediction of aspects from each three scales of daily performance. Score of paranoid, schizoid, avoidance and obsessive-rational were linked negatively with feelings of a relationship. Finally, Nooripour (2015) found that training causes self-esteem enhancement and satisfaction in individuals.

\section{Methodology}

This research method is correlation type. This method surveys the amount of changes of one or more factors in one or more other factors. Regarding to subject and the main purpose of research, this research is practical type and with regard to the way of gathering information, it is questionnaire type and with regard to condition of conducting research, it's fieldwork type. In this research statistical society includes whole married free university students of Rasht and research sciences in 2013-2014 academic semester that 10,485 persons are studying in free university and research sciences. For assigning sample size Morgan table was used that regarding to this table (Table 1), sample size of 714 persons were selected. Simple random method has been used for assigning testers. In this case with regard to introduced married free university students, we gave a score to each of them and required numbers were selected by using the table of random numbers.

\section{Instruments}

Measurement instruments of this research are: five factors Personality questionnaire, NEO-FFI questionnaire in Iran has been normalized by Grosi (1998). Validity of questionnaire was obtained by retest method in 2008 university students within 3 months in order of 83/0, 75/0, 80/0, 79/0, 79/0 for C, A, O, E, N factors. 


\subsection{Self-Esteem Questionnaire}

The second research instrument is cooper smith self-esteem criterion that includes 58 articles which its 8 articles, that is $48,41,34,27,20,13,6$ and 55 are lie detector. Generally its 50 articles are derided on 4 subscales of general self-esteem, social self-esteem, family self-esteem and analytic self-esteem.

For assessing reliability of questionnaire in this research, Cronbach's Alfa for factors of family self-esteem is 059.0, general self-esteem 0.43 , social self-esteem-40/0 and job self-esteem is $46 / 0$. As it has been Cronbach's Alfa reliability coefficient of factors are less but because total Alfa coefficient is high and has been approved, these factors are also approved. Based on the amount of reliability coefficient, Cronbach's Alfa of all factors is also with reliability 67.0 (Table 2).

\subsection{Marital Satisfaction Questionnaire}

For surveying the extent of marital satisfaction, Enrich has been selected that this questionnaire was conducted by Olson, et al. in 1989. First it included 115 closed questions and 12 subscales. By doing this research, 47 articles are reported.

For assessing the reliability of this questionnaire, Cronbach's Alfa is 913.0.

As it has been seen, reliability coefficient of Cronbach's Alfa is approved in a high level (Table 3).

\section{Findings}

Table 4 shows the descriptive indexes for each aspects of questionnaire. Regarding to the table, average and

Table 1. Cronbach's alpha for personality trait factors.

\begin{tabular}{ccc}
\hline Total score & Cronbach's Alpha & Factors \\
\hline & 33.0 & agreeableness \\
& -268.0 & conscientious \\
$564 / 0$ & -04.0 & Flexibility \\
& 5.0 & extroversion \\
& 376.0 & neurosis \\
\hline
\end{tabular}

Table 2. Cronbach's alpha self-esteem factors.

\begin{tabular}{|c|c|c|}
\hline Total score & Cronbach's Alpha & Factors \\
\hline \multirow{4}{*}{$67 / 0$} & 059.0 & Family self-esteem \\
\hline & 48.0 & General self-esteem \\
\hline & -40.0 & Social self-esteem \\
\hline & 46.0 & Job self-esteem \\
\hline
\end{tabular}

Table 3. Cronbach's alpha for marital satisfaction.

\begin{tabular}{ccc}
\hline Total score & Cronbach's Alpha & Factors \\
\hline $91 / 0$ & $91 / 0$ & Marital satisfaction \\
\hline
\end{tabular}

Table 4. Minimum, maximum, average and standard deviation and skew of under studied variables.

\begin{tabular}{|c|c|c|c|c|c|c|c|c|c|c|c|}
\hline & $\begin{array}{c}\text { Marital } \\
\text { satisfaction }\end{array}$ & $\begin{array}{c}\text { Self } \\
\text { esteem }\end{array}$ & Neuroticism & extrovertsion & cheerfulness & flexibility & conscientious & $\begin{array}{c}\text { General } \\
\text { selfesteem }\end{array}$ & $\begin{array}{c}\text { Family } \\
\text { selfesteem }\end{array}$ & $\begin{array}{c}\text { Social } \\
\text { selfesteem }\end{array}$ & $\begin{array}{c}\text { gob } \\
\text { selfesteem }\end{array}$ \\
\hline Minimum & 69 & 22 & 23 & 28 & 28 & 39 & 29 & 9 & 1 & 1 & 2 \\
\hline Maximum & 231 & 46 & 43 & 47 & 47 & 64 & 47 & 21 & 7 & 7 & 8 \\
\hline Average & 164.67 & 33.81 & 33.64 & 3./93 & 38.04 & 52.58 & 39.60 & 15.94 & 4.54 & 3.52 & 4.90 \\
\hline Standard deviation & 26.12 & 5.17 & 4.24 & 4.74 & 3.24 & 4.63 & $3 / 46$ & 2.67 & 1.28 & 1.19 & 1.52 \\
\hline Skew & -0.043 & -0.038 & -0.269 & -0.233 & 0.311 & 0.078 & -0.265 & -0.350 & 0.003 & 0.036 & -0.063 \\
\hline
\end{tabular}


standard deviation of marital satisfaction variable is (26.12) 164.67 and negative skew is -0.048 , self-esteem (5.17) 33.81 and negative skew $-0 / 038$, conscientious (4.24) $33 / 64$ and negative skew. -0.269 , extroversion (4.74) 37.93 and negative skew -0.233 , cheerfulness (24.3) $38 / 04$ and positive skew 0.311 , flexibility.

(4.63) 52.58 and positive skew 0.078 , conscientiousness

(3.46) 39.60 and negative skew -0.265 , general self-esteem

(2.67) 15.94 and negative skew -0.350 , family self-esteem

(1.28) 4.54 and positive skew 0.003 , social self-esteem

(1.19) 3.52 and positive skew 0.036 and job self-esteem

(1.52) 4.90 and negative skew -0.063 .

Table 5 shows the correlation matrix of understudied variables with marital satisfaction. The results show that there was no meaningful relationship between factors of neuroticism, extroversion, cheerfulness, flexibility, conscientious with marital satisfaction. The results show that there was no meaningful relationship between factors of neuroticism, extroversion, cheerfulness, flexibility, conscientious with marital satisfaction $(P>0 / 01)$. Also there was no meaningful relationship between factors of family self-esteem, general self-esteem, social self-steam and job self-esteem with marital satisfaction $(P>0 / 01)$.

The square of correlation coefficient (determination coefficient) shows that variable of conscientious, processes $25 \%$ percent of changes in marital satisfaction $\left(r^{2}=0.254\right)$. Variable of flexibility processes $27 \%$ percent of changes in marital satisfaction $\left(r^{2}=0.278\right)$. Tables $4-7$ assess the whole meaning of model.

As $P<0 / 01$; the model is meaningful. So it can concluded that multiple Regression equation; that is conscientious (SIG-0/000, F-89.55) and flexibility (Sig-0/000, F-50.37) can be predictor of changes in marital satisfaction. In Table 4 the obtained coefficients for Regression have been presented step by step.

For assessing, Beta Coefficient presents the portion of each variables in a size model. The obtained Beta coef-

Table 5. Correlation matrix in surveying the variables of personality traits, self-esteem, and marital satisfaction.

\begin{tabular}{|c|c|c|c|c|c|c|c|c|c|}
\hline & 1 & 2 & 3 & 4 & 5 & 6 & 7 & 8 & 9 \\
\hline Marital satisfaction & 1 & & & & & & & & \\
\hline Neuroticism & -0.037 & 1 & & & & & & & \\
\hline Extroversion & 0.048 & 0.226 & 1 & & & & & & \\
\hline Cheerfulness & 0.035 & 0.408 & 0.137 & 1 & & & & & \\
\hline Flexibility & 0.171 & 0.254 & $0 / .73$ & 0.321 & 1 & & & & \\
\hline Conscientious & 0.504 & 0.001 & -0.077 & -0.091 & 0.035 & 1 & & & \\
\hline General self-esteem & 0.069 & -0.536 & 0.238 & -0.177 & -0.308 & 0.107 & 1 & & \\
\hline Family self-esteem & 0.005 & 0.088 & 0.047 & 0.310 & 0.145 & -0.075 & 0.234 & 1 & \\
\hline Social self-esteem & 0.019 & 0.061 & -0.025 & -0.089 & 0.112 & 0.110 & 0.250 & 0.223 & 1 \\
\hline Job self-esteem & -0.015 & -0.201 & -0.175 & -0.415 & -0.218 & 0.049 & 0.607 & 0.242 & 0.512 \\
\hline
\end{tabular}

Table 6. Multiple correlation between variables of predictor and criterion.

\begin{tabular}{ccccc}
\hline & $(\mathrm{r})$ & $\left(\mathrm{R}_{2}\right)$ & $\Delta\left(\mathrm{R}_{2}\right)$ & Standard error \\
\hline 1. Conscientious & 0.504 & 0.254 & 0.251 & $2 . / 62$ \\
2. Flexibility & 0.527 & 0.278 & 0.272 & $2 . / 30$ \\
\hline
\end{tabular}

Table 7. Test of analyzing multiple regression variance.

\begin{tabular}{|c|c|c|c|c|c|}
\hline & SS & $\mathrm{DF}$ & MS & $\mathrm{F}$ & Sig \\
\hline Regression (conscientious) & $45,827.97$ & 1 & $45,827.97$ & 89.55 & $0 / 00$ \\
\hline The rest & 0.28 & 263 & 511.73 & & \\
\hline \multirow[t]{2}{*}{ Regression (flexibility) } & 134,587 & 2 & $25,053.56$ & & \\
\hline & $50,107.13$ & 262 & 497.35 & 50.37 & 0.000 \\
\hline The rest & 130,308 & & & & \\
\hline
\end{tabular}


ficients in table show that with increasing one unit of standard deviation in conscientious variable as a primary predictor variable in the size of 0.499 (Beta) the unit of standard deviation increases in criterion variable, that is marital satisfaction. With increasing one unit of standard deviation in flexibility variable as a primary predictor variable in the size of 0.154 (Beta), the unit of standard deviation increases in criterion variable that is marital satisfaction. With 0/95\% confidence we can say that among the factors of personality traits, two factors of conscientiousness and flexibility were remained in Regression equation that factor of conscientious and after that factor of flexibility with 15 percent have had the highest impact on marital satisfaction.

Regression linear equation $Y=a+b x$

Flexibility $(0.154)+$ conscientious $(0.499)=$ marital satisfaction

\section{Discussions and Conclusions}

The square of correlation coefficient (determination coefficient) shows that conscientious variable processes $25 \%$ percent of changes in marital satisfaction $\left(r^{2}=0.254\right)$. Extroversion variable processes $27 \%$ percent of changes in marital satisfaction $\left(r^{2}=0.278\right)$. The obtained result is agreement with finding of Rasouli (2013), Mahmmadi Jos Dani (2013), Javaher Niya (2013), Aghaei (2012), Zahiri (2011), Shafiei Motlagh (2010), Shamsolahi (2011), Ticket (2013), Speech (2012), Zarbakhsh (2013), and Jeffery (2001).

In 2013, Ticket surveyed the relationship between personality traits and relationship satisfaction in couples. With helping a model from 14,807 couples from data series of RELATE, he tested a model from direct and indirect relation between personality traits and relationship satisfaction. Also shyness, self-esteem and relationship satisfaction for both parties in a relationship was assessed in his model. Claxitone (2012) surveyed a study on 125 couples who are interested in opposite sex that got married for a long time, personality traits of both parties and relative differences of personality concepts as predictor of marital satisfaction. As it was assumed, each of fire personality factors was correlated meaningfully with life satisfaction. However the central role of neuroticism was pointed well in previous studies, in his study it was shown that conscientious is a feature that has the widest relation with life satisfaction in long-term marriages. This difference between results can be indicative of change during the life, the amount of mental impact on divorce, or overconfidence in younger samples in previous studies and or a mixture of three cases.

In the process of above it is argued that the main survival of family is the result. In the family system, relation factor is high determiner. Proud families have learned the way of interacting and sending message and then have healthy patterns.

Happiness, vivacity, love, respect for each other, relaxing silence and not silence resulting from fear, witticism, flexibility and parents with features of a friend not features of a manager, are such features of families who can say have high self-esteem. While in families who don't have effective relationship, bitter and sardonic humors, ineffective and vague relations and unusable rules exist and this issue is ignored. In the other side confident self-esteem causes that human could control and direct the created actions and if individuals organize their actions and control their thoughts, most of the problems and issues can be solve automatically. In a research which was conducted in 2010, impact of selection factors before marriage on sexual satisfaction of marriage from ecosystem viewpoint was examined in the first year.

A sample of 70 couples filled a questionnaire a few months before marriage that assesses their level of loyalty, self-disclosure, free relations, lasting relationship and self-esteem. In the first year of marriage, their sexual satisfaction was assessed by helping sexual satisfaction index. By helping Regression they found that the best predictors of husband sexual satisfaction before marriage are self-esteem, free relations, and woman stability. The best cases in predicting woman sexual satisfaction is also self-esteem and her free relations and husband faithful communications.

Jeffery (2001) used couples aged between 20 to 85 out of 166 couples for completing his studies and showed that participants who were happier and or with salient behavior, and individuals whose couples had happier character were more satisfied with their marriage. As happiness is a general index for mental balance, the results show that more balanced persons, and individuals with balanced couples were more satisfied with their life. Also some results showed that individuals choose spouses with the same behavior of their own.

Marital satisfaction is a process that is made during life of couples, because it needs conformity of preferences, recognizing personality traits, creating it needs conformity of preferences, recognizing personality traits, creating behavioral rules and forming friendly patterns, It seems that couples who are satisfied and compatible with 
different aspects of life, are agreement with each other. Such a wife and husbands are satisfied with the type and level of their verbal and non-verbal interactions, consider their sexual relations enjoyable and satisfying, plan and manage their financial issues well, prefer their interest to the interest of life family in challenges and disagreements and have high flexibility, they are satisfied with type and quality of spending free time and visiting relatives and finally have common in number and way of training children. In the other side, many people suffer from mental problems a lot and not only they are in crisis, but get the family and society into trouble, too. Several researches have shown that having stability in personality can increase the level of marital satisfaction, welfare, property, success, love and happiness.

Also stability in personality causes the recognition of own feelings and it is used for making proper decision in life. Having meaning and goal in life, feeling of belonging to a grand source, hopeless to God help in difficult situation of life, using social, spiritual supports ... are all resources that individuals can bear less harm in dealing with life pressures. Zarbakhsh (2013) surveyed the relationship between sexual self-esteem and is components with marital satisfaction by a sample of 196 woman athlete in 22 areas of city of Tehran. His statistical analysis showed that there is a positive relationship sexual self-esteem and its components (skill, attractiveness, control, behavioral judgment, compatibility) with life satisfaction.

In the process of obtained results we should say that couples who have high self-esteem, have the personality of interaction with others. Have good interpersonal relationship with others. Meaningless relationship of marital satisfaction and self-esteem is the result of extra emphasize in achieving confirmation and, attention and acceptance, from others with prevents forming confidence and real meaning in person.

So it should be said that feeling of valuation in individuals is more dependent on reaction of others than to his own intrinsic tendencies. Individual with weak and unstable self-esteem have limited vocabulary scope for describing their emotions, of course it is not so that considered couples never feel that have weak self-esteem, but they can't exactly recognize their feeling and then they don't express it, therefore marital satisfaction forms in families who are not senseless, unfriendly, stingy, secluded, fierce, unpredictable, or bad temper. In the other side, couples with high self-esteem have high interaction skills and also these individuals are optimistic and full of hope and humor and see and accept the other people and outside world as they really are. In couples with less self-confidence this issue is inverse because these individuals are somehow pessimistic about their around situations and attribute them to themselves.

Proper relations between couples depend on different factors such as cultural beliefs, academic education and training that person achieves from his family or society. Because proper training by different plans can fairly change their life base.

\section{References}

Aghaei, V. (2012). Investigating the Relationship between Life Style and Doing Religious Beliefs with Marital Satisfaction in Young Married Women Teachers. MA Dissertation, Rasht: Faculty of Humanities, Islamic Azad University.

Bloch, L., Haase, C. M., \& Levenson, R. W. (2014). Emotion Regulation Predicts Marital Satisfaction: More than a Wives' Tale. Emotion, 14, 130-144. http://dx.doi.org/10.1037/a0034272

Cooper, S. (1967). The Antecedents of Self-Esteem. San Francisco, CA: Freeman Press.

Grosi, F. M. (1998). Standardization of Fire-Scale Model Investigating the Analysis of Its Feature and Factor Construct among University Students. Ph.D. Thesis, Tehran: University of Teacher Training.

Javaher Niya, Z. (2013). Role of Natural-Characteristic Factors and Defensive Mechanisms in Marital Satisfaction. Thesis, Ministry of Science, Research and Technology. Tabriz: School of Education and Psychology, University of Tabriz.

Jeffery, S. B., \& Albert, M. (2001). Personality and Temperament Correlates of Marital Satisfaction. Journal of Personality, 6, 93-125.

Nooripour, R., Esmaeili, S., Ghasemzadeh, S., Habibi, M., \& Mirshekari, H. M. (2015). Effects of Life Skills Training on Self-Esteem Enhancement and Marital Satisfaction among Female Addicts. AYER, 1, 72-86.

Parvin, L. A., \& John, A. P. (2002). Personality: Theory and Research. Translation of M. Jafar. Javadi, P. Kadiver, Tehran: Aeizh.

Rasouli, L. (2013). Relationship between Self-Esteem and Communication Beliefs with Marital Satisfaction in Married Women Who Go to Consulting Centers in Tehran Region 2. Thesis, Rasht: Islamic Free University of Rasht.

Solomon, B. C., \& Jackson, J. J. (2014). Why Do Personality Traits Predict Divorce? Multiple Pathways through Satisfaction. Journal of Personality and Social Psychology, 106, 978-996. http://dx.doi.org/10.1037/a0036190 
South, S. C. (2014). Personality Pathology and Daily Aspects of Marital Functioning. Personality Disorders: Theory, Research, and Treatment, 5, 195-203. http://dx.doi.org/10.1037/per0000039

Specht, J., Egloff, B., \& Schmukle, S. C. (2014). The Impact of Life Satisfaction on the Development of the Big Five Personality Traits Personnel Psychology. Psychology reSearches, 52, 621-652.

Shafiei Motlagh, S. (2010). Investigating Simple and Multi-Relationship of Attachment Styles and Personality Traits with Marital Satisfaction and Happiness in Woman and Men of Gachsaran City. MA Dissertation, Ministry of Science, Research and Technology, Esfahan: University of Esfahan.

Shamsolahi, S. (2011). Investigating the Relationship between Personality Traits with Marital Satisfaction of Working Women and Housewives. MA Dissertation, Ministry of Science, Research and Technology. School of Education and Psychology University of Hormozgan.

Tackett, S. L., Nelson, L. J., \& Busby, D. M. (2013). Shyness and Relationship Satisfaction: Evaluating the Associations between Shyness, Self-Esteem, and Relationship Satisfaction in Couples. The American Journal of Family Therapy. 41, 34-45.

Zahiri, S. (2011). Investigating the Relationship of Bias, Intimacy and Self-Disclosure with Marital Satisfaction among Married Employees of Shahid Chamran and Medical Science of Shahid Chamranin Ahvaz. Thesis, Ministry of Science, Research and Technology, Ahvaz: University of Shahid Chamran.

Zarbakhsh, M., Taghavi Dinani, P., \& Mohamadali, R. (2013). The Relationship between Sexual Self-Esteem and All Its Component with Marital Satisfaction in Athletic Women in Tehran. European Online Journal of Natural and Social Sciences, 2, 200-206. 